\title{
Understanding the Pathway of Cancer Information Seeking: Cancer Information Services as a Supplement to Information from Other Sources
}

\author{
Doreen Reifegerste ${ }^{1}\left(\right.$ ) $\cdot$ Magdalena Rosset ${ }^{2} \cdot$ Fabian Czerwinski $^{2} \cdot$ Eva Baumann $^{2} \cdot$ Andrea Gaisser $^{3} \cdot$ Evelyn Kludt $^{3}$. \\ Susanne Weg-Remers ${ }^{3}$
}

Accepted: 23 September 2021 / Published online: 16 November 2021

(c) The Author(s) 2021

\begin{abstract}
Cancer information services (CISs) can play an important role within the pathway of cancer information seeking, but so far, this role is not well understood. Callers $(n=6,255)$ who contacted the largest provider of cancer information in Germany participated in a survey in which they reported their information sources, information level, and needs leading to the call. Persons with prior information from a physician $(n=1,507)$ were compared to people with prior online information $(n=901)$ and people with prior information from both sources $(n=2,776)$. Nearly all callers $(96.7 \%)$ stated prior sources, while physicians and the Internet were the most frequently reported sources. People, who only talked to a doctor before, are more likely to be a patient and in the disease stages during/after the first treatment or with recurrence than prior Internet users. The two groups do not differ in their prior information level but did differ in their information needs. CISs are an important supplement to other sources, while the information repertoire depends on patients' stages during the cancer journey. Specific characteristics and needs of callers with different prior information sources help to individualize the service of CISs and similar providers.
\end{abstract}

Keywords Cancer · Cancer information seeking $\cdot$ Cancer information service $\cdot$ Information sources $\cdot$ Pathway

\section{Introduction}

After a cancer diagnosis, patients and their family members often need information and advice to help them cope with the situation and related challenges. They are confronted with many uncertainties and have to make treatment decisions or support patients [1,2].

One strategy of managing and coping with these uncertainties is to actively seek cancer-related health information from various sources, such as doctors, the Internet, other media, support groups, and (to a lesser extent) cancer

Doreen Reifegerste

doreen.reifegerste@uni-bielefeld.de

1 School of Public Health, Bielefeld University, Universitätsstr. 25, 33615 Bielefeld, Germany

2 Department of Journalism and Communication Research, Hanover University of Music, Drama and Media, Expo Plaza 12, 30539 Hannover, Germany

3 Cancer Information Service, German Cancer Research Center, Im Neuenheimer Feld 280, 69120 Heidelberg, Germany information services (CISs) [3]. In a scoping review of cancer information studies from 2007 to 2017 comparing the preferences for various cancer information channels, it was found that doctors ranked first among patients and caregivers, and the Internet second $[4,5]$. As physicians are no longer the only source of health information, it also seems necessary to look at the sequence of sources people turn to in more detail. Pathways of information seeking within the repertoire of information sources are often looked at within the context of medical consultations [6]. So we already know that online sources are often used to prepare, or follow-up face-to-face encounters with physicians to complement unfulfilled needs and gain autonomy [7]. However, we know little about the role of further information sources, such as CISs, within these pathways.

Understanding the specific characteristics and needs of callers with prior information from different sources can be helpful to better fulfill their individual information and support needs and improve the services of CISs and other cancer-related information providers. The results of such a study could also serve as a basis for the development of 
communication strategies and tailored information resources for helpline operators and medical professionals [8].

Physicians are an important source of information about a diagnosis, treatment, and prognosis [5]. Cancer information from health professionals is trusted most [9], and most people prefer cancer-related information from health professionals [4]. However, doctors often work under rigid time constraints, keeping them from an in-depth conversation with their patients. Some might lack communication skills that encourage patients to talk about psychological concerns [10] or other support needs. Thus, cancer patients are often dissatisfied with how doctors and other health care professionals respond to their information needs [11], see their information demands unmet [1], or have problems expressing their feelings and concerns to their doctors [10]. In addition, family members often feel that their information needs are not taken seriously by medical staff and often face difficulties retrieving information from health professionals [12]. Thus, their information needs (in addition to those of the patients) often remain unfulfilled [2, 13-15].

In contrast, the Internet has increased health and medical information availability in recent decades, providing patients and caregivers with plenty of opportunities to search for cancer-related information [5]. When looking for health information, most people turn to the Internet first [16]. But the multitude of online information and the multiple sources can make it harder for patients and caregivers to find reliable information and properly evaluate (possibly conflicting) information.

Preferences for and evaluation of cancer information from the Internet seem to differ depending on the individual's role as a patient or a caregiver. Although caregivers prefer doctors as an information source, they still mostly use the Internet to obtain information for specific problems [17] and more likely to use the Internet for cancer information than patients [18]. Moreover, they are more satisfied with the Internet as a source for cancer-related information than patients, while patients show higher satisfaction with doctors [19]. An explanation for these results could be that while patients directly contact doctors and other health professionals, their family members and friends often receive much less attention and support [20]. Family members face particular challenges gaining health information and counseling. Still, they are not the primary target group of health care providers, so they depend on additional sources to fulfill their informational needs and actively seek cancer-related information complementary to the information they gain from health professionals [17, 21].

Taken together, different cancer information seekers face different informational challenges, and either source leaves unmet needs for both patients and caregivers. Thus, additional sources that are available and reliable to supplement the primary sources of cancer information are needed.
Accordingly, CISs, in addition to medical staff and other information sources, have become established as easily accessible sources for individually tailored, valuable, and reliable (i.e., evidence-based) information and counseling [22]. CISs are available in many parts of the world. They offer informational and emotional support for patients and their family members and friends via telephone, e-mail, social media, or letter [23]. From CIS evaluation surveys around the world, it is known that people contacting CISs are overall satisfied with the information they receive [23] and that use of the service mostly provides several cognitive and emotional benefits for them [22, 24, 25].

Studies show that cancer survivors use about five different information sources on average when searching for cancer-related information $[5,26]$, and $69 \%$ of cancer patients obtain information from other sources besides their health care providers [27]. This suggests that information from the Internet or the physician alone does not comprehensively satisfy patients' emotional and informational support needs. Such unmet needs can be a predictor for using alternative information sources to gratify remaining information needs [28]. Also, it seems necessary to understand usage patterns of such sources over time [26]. Hence, CISs may supplement information retrieved from other sources used before the CIS call. This assumption is supported by the fact that some CIS callers (26.3\%) had already sought cancer-related information from the Internet before contacting the CIS [29].

So far, prior information behavior has scarcely been considered when analyzing CIS callers because most existing research focuses on using different single sources and does not consider the supplementary role of CISs in the seeking pathway within the repertoire of information sources of cancer patients and their caregivers. Accordingly, to better understand the cancer information journeys of patients and their caregivers and improve the adjustment of information provision and counseling by health care providers and CISs, the personal and needs-related differences of callers with prior information from different sources must be analyzed.

This requires to take into consideration the already known determinants that help to explain the use and preference for health professionals and the Internet as the two major information sources, i.e., the accessibility of different information sources for different groups of information seekers, socio-demographic and cancer-related characteristics, and information-related factors. Studies show that older people are more likely to seek information on cancer than younger people overall [30, 31]. Focusing on the Internet reveals that more younger people prefer to seek cancer-related information on the Internet than older people. In comparison, more older people prefer cancerrelated information from health professionals than younger people [30-34]. Higher educated people would rather seek cancer-related information on the Internet [30,33], while 
persons with a lower level of education turn more to health professionals [32]. In addition to age and education, sex is also associated with cancer information seeking. Women are more likely to seek cancer-related information than men [30, 31, 35-37] and would also contact CISs more often than men [38].

Furthermore, certain cancer-related characteristics can be associated with the information-seeking behaviors of patients and their family members. For example, the information needs of patients and family members are often associated with the cancer stage of the patient and differ throughout the disease [14, 39-44].

When looking at the information needs of people contacting a CIS, the most relevant topics are treatment, prognosis, general cancer information, and psychosocial support; among caregivers, the need for psychosocial support and prevention rank higher than among patients [4].

Hence, users of a CIS appear to have different information needs. They might also differ regarding their perceived prior information level after using different sources - particularly from a doctor or from the Internet - before contacting a CIS. They might be already informed to a certain degree, and it seems very likely that differences in the requests to CISs arise from the use of different sources. But there is little research on individual characteristics explaining the differences between those who gather information from other sources before turning to a CIS. Also, it can be expected that patients and family members who contact CISs differ regarding their support needs depending on the information they have obtained from other sources before. Therefore, this study analyzes CIS callers' prior information sources before contacting the CIS and determinants associated with prior information from the different sources. Thus, our first research question addresses the type of these prior information sources.

RQ1: Which prior information sources do CIS callers have?

As health professionals and the Internet are the two major prior information sources before people call a CIS, the specific research questions regarding the comparison are as follows:

RQ2: How do CIS callers with different prior information sources differ regarding (a) socio-demographics (sex, age, education), (b) cancer-related characteristics (cancer stage, type of caller - patient or family member), and (c) information-related factors (perceived level of prior information, informational needs, use of further information sources after their contact with the CIS)?

In addition, we aimed to analyze the relative impact of these three types of factors:

RQ3: What is the additional explanation value of the three-factor groups?

\section{Method}

\section{Procedure and Participants}

The analysis is based on two large-scale surveys of users of the telephone service of the largest provider of cancer information in Germany, the Krebsinformationsdienst (KID), conducted between April and September 2011 and between June 2016 and April 2017. The KID is a division of the German Cancer Research Center. The service is publicly funded, free of charge, comprehensive, and understandable. The KID also provides information for the general public (e.g., individuals seeking cancer prevention or early detection), journalists, or health care professionals [45]. Callers who identified themselves as any of these were excluded from the analysis.

Thus, only callers being patients or family members of patients were included in the analysis. Those who agreed to participate $(n=4,715$ callers between April and September 2011; $n=4,713$ callers between June 2016 and April 2017) received a questionnaire (2011: postal, 2016: postal or online) within 2 weeks after the contact with KID. The response rate was $67.6 \%(n=3,185)$ in 2011 , and $65.2 \%$ $(n=3,070)$ in 2016 , where $65.2 \%$ participated in the postal and $34.8 \%$ in the online survey. Thus, in total, $n=6,255$ callers participated across the two surveys.

\section{Measures}

From the callers' dataset, sex $(0=$ female; $1=$ male $)$, age (open), education $(0=$ below university entrance degree; $1=$ university entrance degree $)$, type of caller $(0=$ caregiver; $1=$ patient), and stages of cancer were included. The different stages of the disease are described as five phases from cancer diagnosis to palliative care (diagnosis, during the first treatment, after the first treatment, recurrence, and palliative stage). Anonymous data on all KID users and, if applicable, the respective patient, including data on socio-demographic and cancer-related characteristics, were available from the routine CIS contact documentation in an electronic database that serves statistical and quality management purposes. An exception from ethical clearance is granted by the data protection authority for this type of data collection, as callers use KID anonymously, and only nonidentifiable data are collected.

The questionnaire was in German. Perceived level of information before the call was measured with the question: "How informed did you feel before calling the KID?" $(1=$ well; $2=$ not very well; and $3=$ not informed at all). We recorded the answers to $0=$ not (well) informed and 
$1=$ well informed because only very few callers (4\%) reported being completely uninformed.

Information needs and concerns were assessed by giving a list of possible answers to the question: "What did you need when you contacted the CIS?". Respondents could endorse each of the following: general explanation, casespecific information, case-specific decisional support, emotional support, and contact information for further support. To analyze the callers' prior information source before contacting the CIS, they were asked to state the previously used sources of information (talks with health professionals, talks with family/friends, other patients, counseling services, TV/ radio, print media, Internet, online support groups).

Use of further information sources after the call was measured with the statement: "I have/my family member has used or intent/s to use the provided contact for further information." Because the questionnaire was sent out at least some days after the call, the statement included both the actual behavior and the intention but always refers to using the provided contact after the call.

\section{Data Analysis}

To address RQ2, we performed simple statistical independence tests between the three groups across all variables that were later used in the regression model. The vast majority of variables were proportions, so we used Cramer's $V$ to test significant differences among the groups. To test the influence of age, we used a simple ANOVA $F$-test to test the mean differences.

For the logistic regression, we only included callers, who either stated using both doctors and the Internet $(n=2,776)$ as well as those persons with prior information only from doctors $(n=1,507)$ and people with prior online information only $(n=901)$.

The category "Internet-only" was applied to all callers who reported prior information only from online resources. The category "doctor only" was equally applied to all callers who reported their prior information stems from their doctor only (general practitioner and/or specialist/oncologist). Last, the category "both Internet and doctor" was applied to all respondents who reported to have been prior informed by online information as well as from their doctors. We excluded respondents who also used other $(n=862)$ or no sources of prior information $(n=209)$ to avoid confounding influences and to focus on the groups with the two most frequently used prior information sources.

This resulted in a final sample of $n=5,184$ for the hierarchical multivariable logistic regression analysis, which was conducted to predict the type of prior information (doctor vs. Internet vs. both).

As independent variables, we included sex, age, and education as socio-demographic variables in the first block.
After including the cancer-related characteristics (patient's stage of cancer and type of caller) in the second block, the third block (information-related factors) included prior information level, information demands, and the use of further information sources. Data for 2011 and 2016 were analyzed together as the results were very similar. This was included in the model as a control variable to control for possible differences due to the year of data collection. All analyses have been conducted using SPSS ${ }^{\circledR} 26$.

\section{Results}

Concerning RQ1, 96.7\% used different information sources before they turned to the CIS. The average number of prior sources was $M=3.73(S D=1.94)$, while the physicians and the Internet were the most frequently used sources (Table 1).

The age of respondents who used the Internet and/ or physicians as prior sources ranged from 20 to 96 years $(M=58.1 ; S D=13.1)$; the majority were female $(65.5 \%)$ and had a higher education level (52.5\%). About $35 \%$ of respondents were family members or friends who contacted the CIS on behalf of patients. The most relevant information needs were case-specific explanations (85.5\%), case-specific decisional support (72.0\%), and additional sources of support $(20.2 \%)$ (Table 2).

Concerning RQ2, the comparison of descriptive results between the three groups of callers (doctor vs. Internet vs. both as the prior information source) revealed significant differences for some characteristics. Internet-informed callers are significantly younger (53.3 vs. 63.6 years) and better educated ( $58.4 \%$ vs. $40.0 \%$ with university entrance degree) than physician-informed callers (both $p<0.001$ ). Furthermore, for Internet-informed callers, the patient's

Table 1 Prior information sources before contacting the cancer information service $(N=6.255)$

\begin{tabular}{lll}
\hline & $\%$ & $\mathrm{n}$ \\
\hline Medical specialist & 71.8 & 4,491 \\
Oncologist & 65.6 & 4,103 \\
Internet & 60.6 & 3,791 \\
General practitioner & 43.1 & 2,696 \\
Books/brochures & 35.7 & 2,233 \\
Family members/friends & 33.6 & 2,102 \\
Newspapers/magazines & 19.9 & 1,245 \\
Television/radio & 17.5 & 1,095 \\
Social support groups & 12.2 & 763 \\
Customer magazines & 9.8 & 613 \\
Cancer information service & 9.6 & 600 \\
Health insurance & 5.8 & 363 \\
Others & 8.9 & 557 \\
\hline
\end{tabular}


Table 2 Descriptive statistics

\begin{tabular}{|c|c|c|c|c|c|c|}
\hline Category & Variable & $\begin{array}{l}\text { Group 1: informa- } \\
\text { tion from both } \\
\text { the Internet and } \\
\text { from a physician } \\
(n=2,776)\end{array}$ & $\begin{array}{l}\text { Group 2: infor- } \\
\text { mation from the } \\
\text { Internet, but not } \\
\text { from a physician } \\
(n=901)\end{array}$ & $\begin{array}{l}\text { Group 3: Infor- } \\
\text { mation from a } \\
\text { physician, but not } \\
\text { from the Internet } \\
(n=1,507)\end{array}$ & Total $(n=5,184)$ & Group differences \\
\hline \multirow[t]{3}{*}{$\begin{array}{l}\text { Socio-demograph- } \\
\text { ics }\end{array}$} & $\begin{array}{l}\text { Sex of caller: male } \\
(\%)\end{array}$ & 35.6 & 32.4 & 33.7 & 34.5 & $V=.03$ \\
\hline & $\begin{array}{l}\text { Age of caller in } \\
\text { years (mean }[\mathrm{SD}])\end{array}$ & $56.8(12.6)$ & $53.3(14.0)$ & $63.6(12.2)$ & $58.1(13.3)$ & $F=213.3 * * *$ \\
\hline & $\begin{array}{l}\text { High level of edu- } \\
\text { cation }(\%)\end{array}$ & 57.3 & 58.4 & 40.0 & 52.5 & $V=.16^{* * *}$ \\
\hline \multirow[t]{5}{*}{ Cancer stage } & Diagnosis (\%) & 17.7 & 25.2 & 14.2 & 18.0 & $V=.09 * * *$ \\
\hline & First treatment $(\%)$ & 31.1 & 26.1 & 26.2 & 28.8 & \\
\hline & $\begin{array}{l}\text { After first treatment } \\
(\%)\end{array}$ & 24.0 & 18.2 & 29.1 & 24.5 & \\
\hline & Recurrence (\%) & 22.5 & 23.5 & 25.5 & 23.6 & \\
\hline & Palliative (\%) & 4.6 & 7.0 & 5.0 & 5.2 & \\
\hline Type of caller & Patient (\%) & 68.4 & 33.9 & 77.4 & 65.0 & $V=.31 * * *$ \\
\hline Prior-info level & $\begin{array}{l}\text { Perceived level } \\
\text { of pre-informa- } \\
\text { tion }=\operatorname{good}(\%)\end{array}$ & 54.8 & 46.0 & 49.7 & 51.8 & $V=.07 * * *$ \\
\hline \multirow[t]{5}{*}{$\begin{array}{l}\text { Informational } \\
\text { needs }\end{array}$} & $\begin{array}{l}\text { General explana- } \\
\text { tions }(\%)\end{array}$ & 17.4 & 16.9 & 19.6 & 18.0 & $V=.03$ \\
\hline & $\begin{array}{l}\text { Case-specific expla- } \\
\text { nations }(\%)\end{array}$ & 88.1 & 84.2 & 81.6 & 85.5 & $V=.08 * * *$ \\
\hline & $\begin{array}{l}\text { Case-specific deci- } \\
\text { sion support }(\%)\end{array}$ & 76.5 & 61.5 & 70.0 & 72.0 & $V=.13 * * *$ \\
\hline & $\begin{array}{l}\text { Additional sources } \\
\text { of support }(\%)\end{array}$ & 19.9 & 27.1 & 16.7 & 20.2 & $V=.09 * * *$ \\
\hline & $\begin{array}{l}\text { Emotional support } \\
(\%)\end{array}$ & 12.0 & 13.3 & 13.1 & 12.5 & $V=.02$ \\
\hline $\begin{array}{l}\text { Support/further } \\
\text { actions }\end{array}$ & $\begin{array}{l}\text { Used further infor- } \\
\text { mational sources } \\
\text { after the call }(\%)\end{array}$ & 46.7 & 46.7 & 36.0 & 43.8 & $V=.10 * * *$ \\
\hline \multirow[t]{2}{*}{ Data collection } & $\begin{array}{l}\text { (\% Online-2016 } \\
\text { only) }\end{array}$ & 73.7 & 79.6 & 49.3 & 67.7 & $V=.25 * * *$ \\
\hline & $\begin{array}{l}\text { Year of data collec- } \\
\text { tion }(2011 \text { in } \%)\end{array}$ & 50.5 & 52.6 & 52.1 & 51.3 & $V=.02$ \\
\hline
\end{tabular}

In case of proportions, we used Cramer's $V$; in case of means (age only), we used ANOVA $(F)$. Type of caller includes patient vs. family members

${ }^{*} p<.05 * * p<.01 * * * p<.001$

cancer stage is much more likely to be in the very first (diagnosis) or last (palliative) stage. The Internet-informed callers are significantly more often surrogate seekers (i.e., family members or friends) than the physician-informed callers $(66.1 \%$ vs. $22.6 \% ; p<0.001)$ and tend to need more additional sources of support (like brochures, written information material or further contact addresses; $27.1 \%$ vs. $16.7 \%)$ but less case-specific support $(61.5 \%$ vs. $70.0 \%$; both $p<0.001$ ). Finally, they stated more frequently to have used further information sources after their first contact with the CIS $(46.7 \%$ vs. $36.0 \%$; $p<0.001)$.
The results of the logistic regression models (Nagelkerke's $R^{2}=20.8 \%$ ) indicate that the demographic variables (RQ2a) are only significant in the full model when comparing users of both sources with only doctor users. Being female $(O R=1.477, p<0.001)$, being older $(O R$ per year: $1.043, p<0.001)$, and lower educated $(O R=1.597$, $p<0.001)$ increases the likelihood that the prior information source was only a doctor (Table 3 ). In contrast, there are no significant associations when comparing only Internet users and users of both prior sources. 
Table 3 Results of the logistic regression model (DV: source of prior info level ${ }^{\mathrm{a}}$ )

\begin{tabular}{|c|c|c|c|c|c|c|c|c|}
\hline & \multirow[t]{2}{*}{ Category } & \multirow[t]{2}{*}{ Variable } & \multicolumn{2}{|l|}{ Block 1} & \multicolumn{2}{|l|}{ Block 2} & \multicolumn{2}{|l|}{ Block 3} \\
\hline & & & OR & $95 \% \mathrm{CI}$ & OR & $95 \% \mathrm{CI}$ & OR & $95 \% \mathrm{CI}$ \\
\hline \multirow{16}{*}{$\begin{array}{l}\text { Only Internet vs. both } \\
\text { doctor and Internet }\end{array}$} & \multirow[t]{3}{*}{ Socio-demographics } & Sex of caller (female) & 1.116 & {$[.91 ; 1.37]$} & $1.240^{*}$ & {$[1.00 ; 1.53]$} & 1.228 & {$[.99 ; 1.52]$} \\
\hline & & Age of caller (in years) & $.980 * * *$ & {$[.97 ; .99]$} & .995 & {$[.99 ; 1.00]$} & .996 & {$[.99 ; 1.00]$} \\
\hline & & $\begin{array}{l}\text { Level of education (low/ } \\
\text { middle) }\end{array}$ & .897 & {$[.74 ; 1.09]$} & .941 & {$[.77 ; 1.15]$} & .939 & {$[.77 ; 1.15]$} \\
\hline & \multirow[t]{5}{*}{ Cancer stage } & Ref.: Diagnosis & & & & & & \\
\hline & & First treatment & & & $.677 * *$ & {$[.52 ; .89]$} & $.710^{*}$ & {$[.54 ; .94]$} \\
\hline & & After first treatment & & & .909 & {$[.67 ; 1.23]$} & .905 & {$[.67 ; 1.23]$} \\
\hline & & Recurrence & & & .868 & {$[.65 ; 1.16]$} & .901 & {$[.68 ; 1.20]$} \\
\hline & & Palliative & & & .846 & {$[.55 ; 1.31]$} & .856 & {$[.55 ; 1.33]$} \\
\hline & Type of caller & Surrogate seeker & & & $4.318^{* * *}$ & {$[3.50 ; 5.33]$} & $4.071 * * *$ & {$[3.29 ; 5.04]$} \\
\hline & Prior-info level & $\begin{array}{l}\text { Perceived level of pre- } \\
\text { information } \\
\text { (no/less good) }\end{array}$ & & & & & 1.206 & {$[.99 ; 1.47]$} \\
\hline & \multirow[t]{5}{*}{ Informational needs } & General explanations & & & & & .895 & {$[.69 ; 1.16]$} \\
\hline & & $\begin{array}{l}\text { Case-specific explana- } \\
\text { tions }\end{array}$ & & & & & .795 & {$[.59 ; 1.07]$} \\
\hline & & $\begin{array}{l}\text { Case-specific decision } \\
\text { support }\end{array}$ & & & & & $.561 * * *$ & {$[.45 ; .69]$} \\
\hline & & $\begin{array}{l}\text { Additional sources of } \\
\text { support }\end{array}$ & & & & & 1.138 & {$[.91 ; 1.43]$} \\
\hline & & Emotional support & & & & & 1.113 & {$[.83 ; 1.50]$} \\
\hline & Further actions & $\begin{array}{l}\text { Used further informa- } \\
\text { tional sources }\end{array}$ & & & & & .970 & {$[.80 ; 1.18]$} \\
\hline \multirow{16}{*}{$\begin{array}{l}\text { Only doctor vs. both doc- } \\
\text { tor and Internet }\end{array}$} & \multirow[t]{3}{*}{ Socio-demographics } & Sex of caller (female) & $1.518^{* * * *}$ & {$[1.27 ; 1.81]$} & $1.507 * * *$ & {$[1.26 ; 1.81]$} & $1.477 * * *$ & {$[1.23 ; 1.78]$} \\
\hline & & Age of caller (in years) & $1.046^{* * * *}$ & {$[1.04 ; 1.05]$} & $1.044 * * *$ & {$[1.04 ; 1.05]$} & $1.043 * * *$ & {$[1.04 ; 1.05]$} \\
\hline & & $\begin{array}{l}\text { Level of education (low/ } \\
\text { middle) }\end{array}$ & $1.707 * * *$ & {$[1.45 ; 2.00]$} & $1.678 * * *$ & {$[1.43 ; 1.97]$} & $1.597 * * *$ & {$[1.36 ; 1.88]$} \\
\hline & \multirow[t]{5}{*}{ Cancer stage } & Ref.: Diagnosis & & & & & & \\
\hline & & First treatment & & & 1.185 & {$[.91 ; 1.54]$} & 1.184 & {$[.91 ; 1.55]$} \\
\hline & & After first treatment & & & $1.429^{* *}$ & {$[1.10 ; 1.87]$} & $1.397^{*}$ & {$[1.07 ; 1.83]$} \\
\hline & & Recurrence & & & $1.349^{*}$ & {$[1.03 ; 1.76]$} & $1.385^{*}$ & {$[1.06 ; 1.82]$} \\
\hline & & Palliative & & & 1.227 & {$[.79 ; 1.91]$} & 1.270 & {$[.81 ; 1.99]$} \\
\hline & Type of caller & Surrogate seeker & & & $.764 * *$ & {$[.63 ; .93]$} & $.746 *$ & {$[.61 ; .91]$} \\
\hline & Prior-info level & $\begin{array}{l}\text { Perceived level of pre- } \\
\text { information } \\
\text { (no/less good) }\end{array}$ & & & & & $1.313^{* *}$ & {$[1.11 ; 1.55]$} \\
\hline & \multirow[t]{5}{*}{ Informational needs } & General explanations & & & & & 1.184 & {$[.96 ; 1.47]$} \\
\hline & & $\begin{array}{l}\text { Case-specific explana- } \\
\text { tions }\end{array}$ & & & & & $.680^{* *}$ & {$[.54 ; .86]$} \\
\hline & & $\begin{array}{l}\text { Case-specific decision } \\
\text { support }\end{array}$ & & & & & $.698^{* * *}$ & {$[.58 ; .84]$} \\
\hline & & $\begin{array}{l}\text { Additional sources of } \\
\text { support }\end{array}$ & & & & & .808 & {$[.65 ; 1.01]$} \\
\hline & & Emotional support & & & & & .963 & {$[.75 ; 1.24]$} \\
\hline & Further actions & $\begin{array}{l}\text { Used further informa- } \\
\text { tional sources }\end{array}$ & & & & & $.705 * * *$ & {$[.60 ; .83]$} \\
\hline Nagelkerke's $R^{2}\left(\Delta R^{2}\right)$ & & & 10.3 & & $18.5(8.2)$ & & $20.8(2.3)$ & \\
\hline
\end{tabular}

Missing cases were deleted listwise, resulting in $n=3,558$. $O R$, odds ratio; $C I$, confidence interval. All models controlled for the impact of the year of data collection (all n.s.)

${ }^{\text {a }}$ Coding of the dependent variable: $0=$ both doctor and Internet (reference category); $1=$ only Internet; $2=$ only doctor

${ }^{*} p<.05 * * p<.01 * * * p<.001$ 
The results for cancer-related characteristics provide answers to RQ2b. Surrogate seekers (in contrast to patients) are more likely to belong to the group of Internet-informed callers who either only used the Internet before the CIS contact $(O R=4.071, p<0.001)$ or who had both the Internet and the doctor as prior information sources $(O R=0.746$, $p<0.05$ ). Some stages of the cancer trajectory (during or after the first treatment and recurrence) are also strongly associated with prior information sources of the caller.

Concerning RQ2c, some of the information-related factors were associated with the prior information source. While the two groups - users of the Internet and users of both sources - do not differ in their perceived level of prior information, the respondents who felt less well informed were more likely to be informed only by physicians $(O R=1.313, p<0.01)$.

Further significant differences could be identified for callers' informational demands. Seeking case-specific explanations $(O R=0.680, p<0.01)$ and case-specific decisional support $(O R=0.698, p<0.001)$ is much more likely among users of both prior sources compared to physician-informed callers and compared to only online information seekers $(O R=0.561, p<0.001)$.

People with prior online and physician information are significantly more likely to report to have used further information sources after the call to the CIS than physician-only informed callers $(O R=0.705, p<0.001)$.

Overall, the introduction of cancer-related characteristics in model 2 led to a considerable increase in the pseudo- $R^{2}$ value (from 10.3 to $18.5 \%$ ). In contrast, the addition of informational demands and further actions following the contact to the CIS resulted only in a minor advancement regarding this characteristic (from 18.5 to $20.8 \%$ ).

\section{Discussion and Conclusion}

\section{Discussion}

The current study aimed to understand the complementary role of CIS by investigating the sources that patients or relatives have sought before the contact with the CIS and to analyze the factors influencing the pathways of information sources. Nearly all respondents used other sources before contacting a CIS. This fact and the high number of prior sources demonstrate that the CIS serves as an important supplement to information from other sources. Physicians and the Internet were the most frequently used prior sources, which was not surprising as both are popular sources for cancer information [4]. However, the differences between callers with prior information from a doctor and/or from the Internet regarding socio-demographic variables, cancerrelated factors, and information-related factors might explain specific informational needs and gratifications sought from CISs.

Regarding the influence of socio-demographic variables, our results are in line with existing research. Older individuals are more likely to seek information from health professionals [30-34], women more often seek cancer-related information than men independent of the source [30, 31, 35-37], and higher educated persons are more likely to have prior cancer information from the Internet [30, 33].

Regarding cancer-related characteristics, the results regarding the type of caller confirm that patients rather have access to doctors. Thus, they are more likely to have prior information from a physician, while family members are more likely to have used the Internet before contacting a CIS [4]. Our results extend existing research by showing that different stages of the disease seem to be associated with different prior information sources.

Regarding the informational needs of callers to the CIS, it has to be noted that the most relevant informational needs in all groups under investigation are case-specific explanations and decision support. Although there are differences for users on different pathways within the repertoire of cancer information, this indicates that the main function of the CISs' supplementary role is to provide case-specific support. However, in the case of prior information from doctors, this seems surprising as doctors are supposed to provide such case-specific explanations.

The relative explanation value of the three-factor groups suggests that socio-demographics and cancer-related characteristics are the main determinants of information demands and behavior on the cancer information-seeking pathway.

\section{Conclusion}

In summary, our study provides an extension to existing research because of its focus on the process of cancer-related information gathering, while other studies often only focus on contact with the CIS. The fact that nearly all surveyed CIS callers had sought or received information before their counseling requests emphasizes the complementary role of the CIS. This study shows that it is important to consider the sequence and combination of sources within the repertoire of information sources instead of assuming and analyzing their exclusive selection in theoretical concepts and empirical design.

The strengths of the present study are its large sample size and the inclusion of data not only from patients but also from surrogate information seekers. However, like any secondary analysis, the data also has some limitations, which should be considered when interpreting the results. First, this study focused on prior information from a doctor and/or from the Internet of CIS callers. Additional research on using other information sources or combining different information 
sources (also those without contact with the CIS) is required to see how different sources complement each other. Second, this study does not consider whether callers used further information sources after contacting the CIS. We have not analyzed which specific information sources they used afterward and which information demands they had in doing so. Future research should analyze the complete informationseeking pathway within the information repertoire, including interpersonal informal and professional sources and different mobile and social media formats. Third, the lower percentage of participants in the online version of the survey indicates that people who took part in the survey preferred the postal version (2016). Thus, future studies should also check how callers could be motivated to fill in the online version more often.

\section{Practice Implications}

Understanding the specific characteristics and demands of callers with prior information from different sources can help better meet their individual information and support needs and improve the service of CISs and other cancerrelated information providers. This could serve as a basis for the development of communication strategies and tailored information resources for CISs. Although most CIS callers are already quite satisfied with the service, perceive information as helpful, and recommend the service to others, a more tailored pathway could improve the cancer information status of patients and their family members.

Insights into differences between callers with different sources of prior information can facilitate the provision of cancer-related information to CIS users and deduce suggestions for doctors to proactively recommend further information sources (e.g., the contact information of a CIS). A study among German practitioners (not oncologists) in 2011 indicated that only about two-thirds know about the CIS, only about $20 \%$ called themselves, and only about $30 \%$ recommend it to their patients [46]. So far, most CIS users learn about the service from the Internet, and only about $10 \%$ from their health professionals [47]. This might be especially relevant when patients still have unmet information needs, require further explanations, decisional support, or emotionally overwhelmed in the consultation with a physician and thus unable to assimilate all the information discussed. These data show the potential of CISs to support patients and caregivers in understanding cancer-related information and make informed decisions. Similarly, Internet information could also enlist the CIS and other contact addresses as further sources of support and, thus, actively support the pathway of cancer information seeking.

Acknowledgements We would like to acknowledge the German Krebsinformationsdienst (KID) staff members for collecting the data.
Funding Open Access funding enabled and organized by Projekt DEAL.

\section{Declarations}

Conflict of Interest The authors declare no competing interests.

Open Access This article is licensed under a Creative Commons Attribution 4.0 International License, which permits use, sharing, adaptation, distribution and reproduction in any medium or format, as long as you give appropriate credit to the original author(s) and the source, provide a link to the Creative Commons licence, and indicate if changes were made. The images or other third party material in this article are included in the article's Creative Commons licence, unless indicated otherwise in a credit line to the material. If material is not included in the article's Creative Commons licence and your intended use is not permitted by statutory regulation or exceeds the permitted use, you will need to obtain permission directly from the copyright holder. To view a copy of this licence, visit http://creativecommons.org/licenses/by/4.0/.

\section{References}

1. Harrison JD, Young JM, Price MA, Butow PN, Solomon MJ (2009) What are the unmet supportive care needs of people with cancer? A systematic review. Support Care Cancer 17:1117-1128. https://doi.org/10.1007/s00520-009-0615-5

2. Lambert SD, Harrison JD, Smith E, Bonevski B, Carey M, Lawsin C, Paul C, Girgis A (2012) The unmet needs of partners and caregivers of adults diagnosed with cancer: a systematic review. BMJ Support Palliat Care 2:224-230. https://doi.org/10.1136/ bmjspcare-2012-000226

3. Brashers DE (2001) Communication and uncertainty management. J Commun 51:477-497

4. Jo HS, Park K, Jung SM (2019) A scoping review of consumer needs for cancer information. Patient Educ Couns 102:1237-1250. https://doi.org/10.1016/j.pec.2019.02.004

5. Finney Rutten LJ, Agunwamba AA, Wilson P, Chawla N, Vieux S, Blanch-Hartigan D, Arora NK, Blake K, Hesse BW (2016) Cancer-related information seeking among cancer survivors: trends over a decade (2003-2013). J Cancer Educ 31:348-57. https:// doi.org/10.1007/s13187-015-0802-7

6. Caiata-Zufferey M, Abraham A, Sommerhalder K, Schulz PJ (2010) Online health information seeking in the context of the medical consultation in Switzerland. Qual Health Res 20:1050 1061. https://doi.org/10.1177/1049732310368404

7. Lee ST, Lin J, A, (2016) self-determination perspective on online health information seeking: the Internet vs. face-to-face office visits with physicians. J Health Commun 21:714-22. https://doi.org/ 10.1080/10810730.2016.1157651

8. Fennell KM, Heckel L, Wilson C, Byrnes M, Livingston PM (2016) How calls from carers, friends and family members of someone affected by cancer differ from those made by people diagnosed with cancer; analysis of 4 years of South Australian Cancer Council Helpline data, support. Care Cancer 24:26112618. https://doi.org/10.1007/s00520-015-3069-y

9. Shea-Budgell MA, Kostaras X, Myhill KP, Hagen NA (2014) Information needs and sources of information for patients during cancer follow-up. Curr Oncol 21:165-173. https://doi.org/10. $3747 / \operatorname{co} .21 .1932$ 
10. Maguire $P$ (1999) Improving communication with cancer patients. Eur J Cancer 35:1415-1422. https://doi.org/10.1016/S09598049(99)00178-1

11. Arora NK, Johnson P, Gustafson DH, McTavish F, Hawkins RP, Pingree S (2002) Barriers to information access, perceived health competence, and psychosocial health outcomes: test of a mediation model in a breast cancer sample. Patient Educ Couns 47:37-46

12. Oh Y-S (2015) Predictors of self and surrogate online health information seeking in family caregivers to cancer survivors. Soc Work Health Care 54:939-953. https://doi.org/10.1080/00981389.2015. 1070780

13. Echlin KN, Rees CE (2002) Information needs and informationseeking behaviors of men with prostate cancer and their partners: a review of the literature. Cancer Nurs 25:35-41

14. Rees CE, Bath PA (2000) The information needs and source preferences of women with breast cancer and their family members: a review of the literature published between 1988 and 1998. J Adv Nurs 31:833-841

15. Longacre ML (2013) Cancer caregivers information needs and resource preferences. J Cancer Educ 28:297-305. https://doi.org/ 10.1007/s13187-013-0472-2

16. Bangerter LR, Griffin J, Harden K, Rutten LJ (2019) Health information-seeking behaviors of family caregivers: analysis of the health information national trends survey. JMIR Aging 2:e11237

17. Kinnane NA, Milne DJ (2010) The role of the Internet in supporting and informing carers of people with cancer: a literature review, support. Care Cancer 18:1123-1136. https://doi.org/10. 1007/s00520-010-0863-4

18 James N, Daniels H, Rahman R, McConkey C, Derry J, Young A (2007) A study of information seeking by cancer patients and their carers. Clin. Oncol. (R Coll. Radiol) 19:356-62. https://doi. org/10.1016/j.clon.2007.02.005

19. Pecchioni LL, Sparks L (2007) Health information sources of individuals with cancer and their family members. Health Commun 21:143-151. https://doi.org/10.1080/10410230701307162

20. Kirschning S, von Kardorff E (2007) Welche Informationen suchen internetnutzende Angehörige krebskranker Frauen und Männer? Helfen die gefundenen Informationen bei der Bewältigungsarbeit? Med Klin 102:136-140. https://doi.org/10.1007/ s00063-007-1014-7

21. Yuen EYN, Dodson S, Batterham RW, Knight T, Chirgwin J, Livingston PM (2016) Development of a conceptual model of cancer caregiver health literacy. Eur J Cancer Care (Engl) 25:294-306. https://doi.org/10.1111/ecc.12284

22. Clinton-McHarg T, Paul C, Boyes A, Rose S, Vallentine P, O'Brien L, O'Brien L (2014) Do cancer helplines deliver benefits to people affected by cancer? A systematic review. Patient Educ Couns 97:302-309. https://doi.org/10.1016/j.pec.2014.09.004

23. Boltong A, Byrnes M, McKiernan S, Quin N, Chapman K (2015) Exploring the preferences, perceptions and satisfaction of people seeking cancer information and support: implications for the cancer council helpline. Aust J Cancer Nurs 16:20

24. Livingston PM, White VM, Hayman J, Maunsell E, Dunn SM, Hill D (2010) The psychological impact of a specialist referral and telephone intervention on male cancer patients: a randomised controlled trial. Psychooncology 19:617-625. https://doi.org/10. 1002/pon.1609

25. Boltong A, Ledwick M, Babb K, Sutton C, Ugalde A (2017) Exploring the rationale, experience and impact of using Cancer Information and Support (CIS) services: an international qualitative study, support. Care Cancer 25:1221-1228. https://doi.org/ 10.1007/s00520-016-3513-7

26. Blanch-Hartigan D, Blake KD, Viswanath K (2014) Cancer survivors' use of numerous information sources for cancer-related information: does more matter? J Cancer Educ 29:488-496. https://doi.org/10.1007/s13187-014-0642-x

27. Walsh MC, Trentham-Dietz A, Schroepfer TA, Reding DJ, Campbell B, Foote ML, Kaufman S, Barrett M, Remington PL, Cleary JF (2010) Cancer information sources used by patients to inform and influence treatment decisions. J Health Commun 15:445-463. https://doi.org/10.1080/10810731003753109

28. Lee SY, Hawkins R (2010) Why do patients seek an alternative channel? The effects of unmet needs on patients' health-related Internet use. J Health Commun 15:152-166. https://doi.org/10. 1080/10810730903528033

29. Hardyman R, Hardy P, Brodie J, Stephens R (2005) It's good to talk: comparison of a telephone helpline and website for cancer information. Patient Educ Couns 57:315-320. https://doi.org/10. 1016/j.pec.2004.08.009

30. Heimer A, Henkel M (2012) Bedarf an Krebsinformation in der Bevölkerung. Analyse des Informationsverhaltens von Ratsuchenden. Repräsentative Befragung im Auftrag des Krebsinformationsdienstes des Deutschen Krebsforschungszentrums: [Analysis of information seeking of people with counseling requests: representative survey on behalf of the German cancer information service of the German cancer research center], Akademische Verlagsgesellschaft AKA, Heidelberg

31. Gaisser A (2012) Bedarf an Krebsinformation in Deutschland: was für wen und wie? Repräsentative Befragung: [Cancer information needs in Germany: what for whom and how? Representative survey]. Forum 27:259-264. https://doi.org/10.1007/ s12312-012-0803

32. Arora NK, Finney RLJ, Gustafson DH, Moser R, Hawkins RP (2007) Perceived helpfulness and impact of social support provided by family, friends, and health care providers to women newly diagnosed with breast cancer. Psychooncology 16:474486. https://doi.org/10.1002/pon.1084

33. Helft PR, Eckles RE, Johnson-Calley CS, Daugherty CK (2005) Use of the Internet to obtain cancer information among cancer patients at an urban county hospital. JCO 23:4954-4962. https:// doi.org/10.1200/JCO.2005.09.621

34. Bennett JA, Cameron LD, Whitehead LC, Porter D (2009) Differences between older and younger cancer survivors in seeking cancer information and using complementary/alternative medicine. J Gen Intern Med 24:1089-1094. https://doi.org/10. 1007/s11606-009-0979-8

35. Basch EM, Thaler HT, Shi W, Yakren S, Schrag D (2004) Use of Internet resources by patients with cancer and their companions. Cancer 100:2476-2483

36. Manierre MJ (2015) Gaps in knowledge: tracking and explaining gender differences in health information seeking. Soc Sci Med 128:151-158. https://doi.org/10.1016/j.socscimed.2015. 01.028

37. Monnier J, Laken M, Carter CL (2002) Patient and caregiver interest in Internet-based cancer services. Cancer Pract 10:305310. https://doi.org/10.1046/j.1523-5394.2002.106005.x

38. Rosset M, Reifegerste D, Baumann E, Kludt E, Weg-Remers S (2019) Langzeittrends beim Krebsinformationsdienst (KID) [Trends in cancer information services over 25 years]. Bundesgesundheitsbl Gesundheitsforsch Gesundheitsschutz 62:1120-1128. https://doi.org/10.1007/s00103-019-02996-w

39. Manfredi C, Czaja R, Buis M, Derk D (1993) Patient use of treatment-related information received from the cancer information service. Cancer 71:1326-1337. https://doi.org/10.1002/ 1097-0142(19930215)71:4\%3c1326:AID-CNCR2820710426\% 3e3.0.CO;2-K

40. Mills ME, Sullivan K (1999) The importance of information giving for patients newly diagnosed with cancer: a review of the literature. J Clin Nurs 8:631-642 
41. Nagler RH, Gray SW, Romantan A, Kelly BJ, DeMichele A, Armstrong K, Schwartz JS, Hornik RC (2010) Differences in information seeking among breast, prostate, and colorectal cancer patients: results from a population-based survey. Patient Educ Couns 81(Suppl):S54-62. https://doi.org/10.1016/j.pec. 2010.09.010

42. Rutten LJF, Arora NK, Bakos AD, Aziz N, Rowland J (2005) Information needs and sources of information among cancer patients: a systematic review of research (1980-2003). Patient Educ Couns 57:250-261. https://doi.org/10.1016/j.pec.2004.06. 006

43. Schmidt A, Wesselmann S, Kowalski C (2015) Informationsbedürfnisse und Informationsprozesse in zertifizierten Zentren: [Information needs and information processes in certified centers]. Forum 30:218-223. https://doi.org/10.1007/ s12312-015-1298-0

44 Squiers L, Finney Rutten LJ, Treiman K, Bright MA, Hesse B (2005) Cancer patients' information needs across the cancer care continuum: evidence from the cancer information service.
J Health Commun 10(Suppl 1):15-34. https://doi.org/10.1080/ 10810730500263620

45. German Cancer Research Center (2021) German cancer information service https://www.nct-heidelberg.de/en/for-patients/couns eling-services/cancer-information-service.html. Accessed $10 \mathrm{Nov}$ 2021

46. Heimer A, Henkel M (2012) Bedarf an Krebsinformation in Fachkreisen: [Need for cancer information among experts], Heidelberg

47. Gaisser A, Sonnet M, Weg-Remers S (2016) Wo suchen und finden Krebspatienten verlässliche Informationen?: [Where do cancer patients seek and find reliable information?]. Forum 31:53-58. https://doi.org/10.1007/s12312-015-0010-8

Publisher's Note Springer Nature remains neutral with regard to jurisdictional claims in published maps and institutional affiliations. 